\title{
Automated 2D-HPLC Method for Characterization of Protein Aggregation with In-Line Fraction Collection Device
}

\author{
Abasha Williams $^{\mathrm{a}}$, Erik K. Read ${ }^{\mathrm{a}, \mathrm{b}}$, Cyrus D. Agarabi $^{\mathrm{a}}$, Scott Lute ${ }^{\mathrm{a}}$, Kurt A. Brorson ${ }^{\mathrm{a}}$ \\ ${ }^{\mathrm{a}}$ Food and Drug Administration, Center for Drug Evaluation and Research, Office of Product Quality, Office of \\ Biotechnology Products, Division of Biotechnology Review and Research II, Silver Spring, MD \\ ${ }^{\mathrm{b}}$ Present Address: AstraZeneca, Manufacturing Sciences and Technology, Rockville, Maryland
}

\author{
*Corresponding author: \\ Kurt A. Brorson \\ FDA/CDER/OPQ/OBP/DBRRII \\ White Oak, Building 72, Room 2220 \\ 10903 New Hampshire Ave, \\ Silver Spring, MD 20993 \\ Tel: (301) 796- 2193 \\ Email: kurt.brorson@fda.hhs.gov
}




\begin{abstract}
Monoclonal antibodies are mainly produced by mammalian cell culture, which due to its complexity, results in a wide range of product variants/isoforms. With the growing implementation of Quality by Design (QbD) and Process Analytical Technology (PAT) in drug manufacturing, monitoring and controlling quality attributes within a predefined range during manufacturing may provide added consistency to product quality. To implement these concepts, more robust analytical tools could reduce the time needed for monitoring quality attributes during upstream processing. The formation of protein aggregates is one such quality attribute that can lead to safety and efficacy issues in the final drug product. Described in this study is a fully automated two-dimensional high performance liquid chromatography (2D-HPLC) method for characterizing protein aggregation of crude inprocess bioreactor samples. It combines protein A purification and separation by size exclusion into a single analytical module that has the potential to be employed at-line within a bioprocessing system. This method utilizes a novel in-line fraction collection device allowing for the collection of up to twelve fractions from a single sample or peak which facilitates the subsequent linked analysis of multiple protein peaks of interest in one chromatography module.
\end{abstract}

Keywords: 2D-HPLC, Protein Aggregation, PAT, QBD, Heart-cutting, Monoclonal antibody purification 


\section{Introduction}

The concept of Quality by Design (QbD), a risk-based approach to building product quality into the manufacturing process [1], was first introduced by the U.S. Food and Drug Administration (FDA) in their Pharmaceutical cGMPs for the $21^{\text {st }}$ Century: A Risk Based Approach initiative [2]. Subsequent guidance's followed from the International Conference on Harmonisation of Technical Requirements for Registration of Pharmaceuticals for Human Use (ICH) [3-6]. QbD implementation is based on an increased understanding of both the product and cell culture processes, and is contrary to the traditional reliance on batch testing for product quality at the end of manufacturing to meet rigorous specification requirements. An important tool for QbD is the concept of Process Analytical Technology (PAT) in which real-time automated decision making drives the manufacturing process to control product quality based on a monitoring of critical quality attributes (CQAs) and critical process parameters (CPPs) in combination with multivariate data analysis [7,8]. This concept is outlined in the guidance provided by the U.S. FDA, PAT - A Framework for Innovative Pharmaceutical Development, Manufacturing, and Quality Assurance [9].

In monoclonal antibody (mAb) development, the implementation of QbD and PAT requires many considerations due to the complexity of the mammalian cell culture process [10]. Thus, additional tools that are both rapid and robust are needed that reduce the time gap between measurement and real-time decision making, allowing PAT based management of CQAs within a predefined range during the actual cell culture process [11, 12]. The formation of protein aggregates during mAb production is one such quality attribute that is known to occur as early as the cell culture process. Aggregate formation can be affected by $\mathrm{pH}$, temperature, and dissolved oxygen within the bioreactor system as well as media components [13-15]. Detecting and then inhibiting the formation of small aggregates during upstream processing would be an ideal strategy to ensure more reliable product quality. In theory, this could minimize the subsequent nucleation of higher molecular weight species that can lead to reduced activity and immunologic problems $[16,17]$.

We have established an automated method for the characterization of the multiple protein peaks that can result due to aggregation using two-dimensional high-performance liquid chromatography (2D-HPLC), even in very complex test articles. Our first dimension is protein A affinity chromatography (ProA), which allows for specific capture of $\mathrm{mAb}$ from complex bioreactor samples that may contain media components, host cell proteins, and DNA. This is then followed immediately in the second dimension by size-exclusion chromatography (SEC), which is a well-established assay employed within the biopharmaceutical industry for the quantification of soluble protein aggregates $[18,19]$. Our method builds upon previous advances in coupled ProA and SEC chromatography that utilized comprehensive 2D-HPLC, to transfer the entire first-dimension eluent to the second dimension for additional analysis [20-22], by providing more capability in sampling with the addition of a unique multiple-port fraction collection device placed between the two columns. The in-line fraction collection device was designed to enable the collection of up to twelve fractions, and is placed in-line with an existing 2D-HPLC system, in a manner previously described as a multi-loop device in metabolomics studies [23]. It facilitates 2D 
chromatography through automated column switching using a heart-cutting technique, where distinct fractions from peaks of interest, or multiple fractions of an individual peak, are collected and subsequently transferred from column one onto column two [23]. By placing the fraction collection device in-line with the HPLC system in this way, we expedite the analysis of multiple protein peaks from column one in a rapid, high-throughput manner that could yield more valuable information for protein characterization than from previous methods. If fully implemented, this system could enable cell culture decision-making to reduce aggregation during upstream processing.

\section{Materials and Methods}

\subsection{Chromatographic Materials and mAb Sample}

The following columns and reagents were used during the development of the 2D-HPLC method described herein: POROS A20 column, 4.6mm×50mm (Applied Biosystems, Foster City, CA); Advanced Bio SEC 300Å column, 4.6mm×150mm (Agilent Technologies, Santa Clara, CA); 10X PBS (Hoefer, Holliston, MA); acetic acid, glacial $\geq 99.7 \%$ w/w (Fisher Chemical, Fair Lawn, NJ); SEC protein standard mix from the Gel Filtration Calibration Kit (GE Healthcare, Piscataway, NJ) consisting of Thyroglobulin, Aldolase, Ovalbumin, and Ribonuclease A and prepared as specified by the manufacturer's instructions. In addition, a thermallystressed mAb sample designed to mimic the multiple protein peaks that may arise due to protein aggregation and fragmentation was used. This sample consists of $10 \mathrm{mg} / \mathrm{ml}$ of a humanized $\mathrm{IgG} 1$ subjected to $65^{\circ} \mathrm{C}$ insult for 3 days. Confirmation of protein aggregation and fragmentation of our model IgG was conducted by direct analysis of the sample by SEC (Figure 1). This column was maintained at $40^{\circ} \mathrm{C}$ with a $1 \mathrm{X}$ PBS mobile phase and 0.5 $\mathrm{ml} / \mathrm{min}$ flow rate.

\subsection{In-line Fraction Collection Device}

We aimed to develop a multiple port fraction collection device comparable to commercially available 2D sampling systems [24] with the ability to accommodate up to twelve sample loops. For practical reasons we collected up to 10 fractions ( 2 are used for waste and/or bypass). The device consists of two electronicallycontrolled 12-position valve systems (Agilent 12/13 SelValves) with each corresponding valve connected with $100 \mu 1$ stainless steel sample loops (Figure 2A). A schematic representation of the valve configuration for this system is depicted in Figure 2B, where flow originating from the inlet port of the top valve system is directed through the open valve and connected sample loop, and exits via the outlet port of the bottom valve system. It is important to note, that only one of the twelve rotating valves can be in the open position at any given time. As a result, coordinated switching of the valves' of the in-line fraction collection device allows for isolation and subsequent release of individual fractions of interest within the sample loops.

\subsection{HPLC System Configuration}


An Agilent 1200 Series HPLC system was used for the development of the 2D-HPLC methods described in this paper. The HPLC system consists of two quaternary pumps with degassers that provide the capability to control up to eight buffers or solvents. The first pump employs a temperature-controlled autosampler for sample loading, while the second utilizes the in-line fraction collection device for sample injection. Columns 1 and 2 are housed in a shared temperature-controlled multiple column compartment with integrated valve module with each column utilizing its own UV detector (Table 1).

Figure 3 depicts a schematic representation of how the fraction collection device is incorporated in-line with the HPLC system for added 2D functionality. This configuration was designed to allow for continuous flow of buffer through both columns regardless of the HPLC valve position. When the HPLC valve is in the $1 \rightarrow 10$ position (clockwise), flow originating from Pump 1 would load sample from the autosampler to column 1. Flow is then passed through a UV detector (D1), operated at $280 \mathrm{~nm}$, prior to being directed to the in-line fraction collector for automated sample isolation. Any remaining sample flow through is directed to waste. A second pump (Pump 2) is used to concurrently allow for continuous flow of buffer to column 2. Once the HPLC valve module is switched to the $1 \rightarrow 2$ position (counter-clockwise), flow from Pump 2 is instead directed first to the inline fraction collector and then to column 2. This allows for the automated release of isolated samples collected by the fraction collector to be loaded onto column 2 and then through a second UV detector (D2) at $280 \mathrm{~nm}$. Pump 1 will again continue to provide buffer flow to column 1.

\subsection{Analysis of Chromatograms}

The resulting ProA and SEC chromatograms obtained from this module should be able to offer useful data for evaluating titer and protein aggregation, respectively. To provide a reference for antibody titer in the first dimension, a standard curve for peak absorbance at $280 \mathrm{~nm}\left(\mathrm{~A}_{280}\right)$ was generated for the POROS A20 column (Figure 4). Samples of known protein concentrations were resolved on the ProA column using the aforementioned method and with an injection volume of $100 \mu \mathrm{l}$. From the slope of this standard curve, the limit of detection (LOD) and limit of quantitation (LOQ) where determined to be $0.016 \mathrm{mg} / \mathrm{ml}$ and $0.052 \mathrm{mg} / \mathrm{ml}$, respectively.

In order for the SEC assay to be useful as an analytical method; however, further consideration must be taken in regards to column loading from the in-line fraction collection device. Thus, we first measured the void volume $\left(V_{o}\right)$ of the second dimension column resulting from the sample loops of the in-line fraction collector. To achieve this, we used a luer lock syringe with adaptor to manually fill the first two sample loops of the fraction collector with $100 \mu \mathrm{l}$ of Blue Dextran $2000(0.25 \mathrm{mg} / \mathrm{ml})$, a polymer widely used to determine $V_{o}$. Blue Dextran was similarly loaded onto the second dimension column at 10 and $20 \mathrm{~min}$ at a flowrate of $0.5 \mathrm{ml} / \mathrm{min}$. For further confirmation, we repeated the manual filling of the first two sample loops of the in-line fraction collection device with Blue Dextran, but loaded it onto the column at $0 \mathrm{~min}$. The resulting $V_{o}$ for each sample loop reported in 
Table 4 , is the elution volume $\left(V_{e}\right)$ of the first Blue Dextran peak and is calculated from the elution time $\left(t_{e}\right)$ and the flowrate $(F)$ of the mobile phase.

$$
V_{e}=t_{e} * F
$$

We observed slight differences in $V_{o}$ for sample loops one and two (Table 2). However, we do not note any significant difference in $V_{o}$ when Blue Dextran is loaded at varying time points from the same sample loop (Table 2). $V_{o}$ for all twelve of the sample loops of the in-line fraction collection device can additionally be determined using this same procedure (data not shown).

To set a reference for molecular weight determination, as evaluated by the elution volume of varying molecular weight proteins resolved at $\mathrm{A}_{280}$ in the second dimension, sample loops one and two of the in-line fraction collection device were manually syringe filled with $100 \mu \mathrm{l}$ of an SEC protein standard mixThyroglobulin (669 kDa), Aldolase (158 kDa), Ovalbumin (44 kDa), and Ribonuclease A (13.7 kDa)—and loaded onto column two at 10 and $20 \mathrm{~min}$ at a flowrate of $0.5 \mathrm{ml} / \mathrm{min}$ (Figure 5). As anticipated, the difference in $V_{o}$ for each of the sample loops caused small discrepancies in $V_{e}$ for each SEC standard protein after loading onto column two from sample loops one and two (Table 2). Therefore, $V_{e}$ for each standard protein was converted to a partition coefficient $\left(K_{a v}\right)$ as depicted in Table 2. This value describes the retention of the protein in the mobile phase, with smaller molecular weight proteins having a larger $K_{a v}$, and is obtained using the $V_{o}$ for the particular sample loop utilized and the geometric column volume $\left(V_{c}\right)$ determined from the radius $(r)$ and length $(l)$ of the SEC column.

$$
\begin{gathered}
K_{a v}=V_{e}-V_{o} / V_{c}-V_{o} \\
V_{c}=\pi r^{2} l
\end{gathered}
$$

The resolution of the SEC standard proteins in the second dimension following its loading from sample loops one and two were then evaluated in terms of $K_{a v}$. As shown in Table 2, the percent error of $K_{a v}$ for each of the standard proteins loaded from sample loop two is well below $1 \%$ when compared to the $K_{a v}$ for the same standard protein loaded from sample loop one. This implies that the in-line fraction collection device does not have altered resolution profiles following loading onto the second dimension column, despite the small discrepancy in $V_{o}$ between the different sample loops. Therefore, the elution peaks from each sample loop and loading time point could be normalized for elution peak time comparison to a single standard curve of log molecular weight versus $K_{a v}$ (Figure 6) for confirmation of placement within a molecular weight range and to assist in peak calling between aggregates, monomers and fragments. 


\section{Results and Discussion}

\subsection{D-HPLC Method for Rapid Protein A and SEC Characterization}

An automated ProA-SEC 2D-HPLC method was designed to provide a rapid SEC based analysis of protein aggregation. To overcome matrix effects caused by potentially complex test articles, the first dimension of chromatography is ProA-HPLC, selectively capturing the antibody before the SEC-HPLC step. Our method differs from previously reported systems by placing a fraction collection device between the two columns. This fraction collection device consists of two rotating valves, each with 12 sample positions (Figure 2A). Sample loops are placed between the two valve systems so that sample loop one connects to the inlet/outlet ports of both valves at port one, sample loop two to the inlet/outlet ports of both valves at port two, etc. all the way to loop twelve; port thirteen on both valves are connected to the column switching valve (Figure 2B). This allows for volume based $(100 \mu \mathrm{l})$ peak isolation or fractionation within the sample loops, which are subsequently analyzed individually by the second chromatography step. This is advantageous because peak tails or secondary peaks can often contain aggregated forms where separate analysis will enable a better understanding of the test article.

To isolate fractions in the first dimension, the HPLC valve module must be in the $1 \rightarrow 10$ position (Figure $3 \mathrm{~A})$, to briefly shunt liquid to the in-line fraction collector. Thermally-aggregated mAb was used as a test article and run on a POROS A20 ProA column maintained at $40^{\circ} \mathrm{C}$ (Figure 7A). A flow rate of $4 \mathrm{ml} / \mathrm{min}$ and a $100 \mu \mathrm{l}$ injection volume were used. As expected, unbound host cell proteins and DNA are washed from the column by $1 \mathrm{X}$ PBS during a washing step (0-2.5 min), while $\mathrm{IgG}$ proteins are reversibly bound to the protein A resin. IgG is then eluted from the column by a $0-100 \%$ linear gradient using $0.1 \mathrm{M}$ acetic acid at $\mathrm{pH} 2.8$ (2.5-6.5 min). As the sample had been force-degraded, a main peak (presumably intact antibody) was evident, proceeded by a frontal peak (probably aggregates, fragments and partially denatured antibody). To further characterize the two resulting antibody peaks, $100 \mu \mathrm{l}$ fractions are concurrently collected through rapid automated switching of the valves' of the in-line fraction collection device (Table 3) using a standard heart-cutting technique (Figure 7A). Please note that care must be taken when timing the collection of fractions to account for dead volume in tubing from the UV detector (D1) to the in-line fraction collector.

Following the elution step, $1 \mathrm{X}$ PBS is returned to the ProA column for re-equilibration. The HPLC valve is also switched to the $1 \rightarrow 2$ position (Figure $3 \mathrm{~B}$ ) in order to direct the effluent flow from column one to waste, while changing the direction of flow from the in-line fraction collection device to the second dimension column. Automated switching of the valves of the in-line fraction collection device is then used to sequentially load fractions within the sample loops onto an Advanced Bio SEC 300Å column (Figure 7B-C) for separation and comparison to $K_{a v}$ values from our standard curve (Table 4). This column was maintained at $40^{\circ} \mathrm{C}$ for chromatogram consistency with a 1 X PBS mobile phase and $0.5 \mathrm{ml} / \mathrm{min}$ flow rate. Timing for the automated switching of the valves of the in-line fraction collector, as outlined in Table 3, provides ample time (10 minutes) to resolve each isolate before the next captured fraction is loaded onto the column. As can be seen, the bulk of the $\mathrm{A}_{280}$ activity in the main protein A peak eluted from the SEC column in a pattern consistent with largely intact 
antibody, with a few fragments. The pre-peak eluted in a complex pattern, with a main doublet peak at about the same elution point as monomer or small aggregates, followed by separate fragment peaks. From a bioprocessing perspective, the result from our method would support a peak cutting purification strategy for the protein A column. Based on the $2^{\circ}$ SEC chromatogram, the frontal peak contains undesirable impurities and should be discarded, while the main peak may still be acceptable for further processing, pending additional analysis.

\subsection{An Alternative 2D-HPLC Method for In-Depth Peak Analysis}

As a second system test, our automated method was utilized for a more comprehensive analysis of protein aggregation through a series of sequential heart-cutting fractionations. To implement the more complex method, we again injected $100 \mu \mathrm{l}$ of our thermally-aggregated mAb sample, and implemented the same ProA-SEC 2DHPLC procedure as previously described. However, the automated timing of the fractions collected by the fraction collection device was compressed to instead isolate multiple segments of the resulting protein peaks of the heat treated sample captured in the first dimension (Figure 8A and Table 5). This results in the additional detection of protein aggregates from the secondary protein A peak by resolution of monomer, aggregates and fragments on the SEC column in the second dimension (Figure 8B) and analysis of $K_{a v}$ (Table 6). As can be seen in Figure 8B, earlier multi-loop fractions exhibit more peak tailing in the second SEC dimension than the two major peaks. This again is consistent with the leading peak on the first protein A dimension containing a higher percentage of undesirable fragments than the major peak from the first dimension. This alternative method provides a more in-depth analysis of peak composition when compared to other 2D-ProA-SEC methods in the literature. Previous methods either do not use a switching valve $[20,22]$ or do not utilize one capable of isolating multiple fractions for individual analysis [21]. It should be noted that because the in-line fraction collection device only isolates part(s) of the overall protein A peaks, the overall method should not be expected to provide mass-balance between input analyte and the sum of the SEC peaks. Rather, it is an analytical dimension that provides an indirect measurement of the relative amount of monomer or aggregates in the different isolated areas of the protein A peak.

\section{Conclusion}

SEC is widely utilized in the biopharmaceutical industry to determine mAb aggregation levels, but in the case of complex test articles like bioreactor samples, initial removal of cell impurities and isolation of the product is required. This paper outlines a 2D-HPLC module that combines protein A purification and peak fractionation followed by SEC into a single, fully-automated chromatographic step. Although previous studies have made advances in the application of coupled ProA-SEC using comprehensive 2D-HPLC chromatography [20-22], we integrate an in-line fraction collection device for a two-dimensional heart-cutting approach with an existing HPLC system between the two columns. Having the ability to capture up to twelve fractions following initial capture allows for a more in-depth analysis of IgG aggregates and monomer peaks in the second dimension. Multi-loop 
devices have been previously described for metabolomics studies [23], but here we demonstrate use in a biopharmaceutical analytics setting. Another major benefit of this method is a reduction in the time required for chromatographic analysis. However, the ability to utilize the in-line fraction collection device also provides additional benefits. It keeps the lower $\mathrm{pH}$ mobile phase used with the ProA column, which may cause a decrease in the recovery of aggregates $[20,22]$ from passing through the SEC column.

Other column combinations used for mAb characterization have previously been implemented using comprehensive 2D-HPLC techniques, but may benefit from the heart-cutting approach outlined in this study. . For example, a previous study has demonstrated the usefulness of combining protein A and cation exchange to decrease the time needed to monitor mAb charge variants, or isoforms, during production processes [26]. SEC or ion exchange could also be used in the first dimension to isolate individual mAbs by size or isoforms and then separate each isolate separately in the second dimension. Proof of concept of this was provided in a study using heat-stressed mAb subjected to SEC, followed by reverse-phase (RP) chromatography in the second dimension to separate by hydrophobicity [26]. These same researchers additionally applied there 2D-HPLC samples directly onto a mass spectrometer (MS) for rapid identification of the resulting peaks and were able to isolate different components with similar RP retention time. Alternatively, MS was directly coupled to a two-dimensional cationexchange (CEX)-RP assay by researchers using intact Rituximab as a test article which allowed for the detection of multiple variants [27]. RP chromatography; however, can sometimes provide difficulty in resolving intact mAb so Alvarez et al. alternatively utilized RP trap cartridges (a low resolution RP columns) to desalt fractions from first dimension eluents by either ion exchange or tandem SEC columns in preparation for direct MS analysis [28]. Another interesting combination would include combining ion-exchange and SEC-MALS (multi-angle light scattering) for an IEC-SEC-MALS 2D protein separation by charge variants and size. Alternatively, twodimensional applications related to the detection of host cell protein impurities (high-pH RP/low-pH RP coupled to MS) [29, 30], confirming antibody-drug conjugate structure (hydrophobic interaction-RP-MS) [31], or comparing biosimilars to the original mAb compound (CEX-RP, RP-RP, or hydrophilic interaction-RP coupled to MS) [32, 33] may also be considered.

MAbs or other heterogeneous protein analytes can be complex, especially in stability studies. Thus, it may be useful to have the capability to collect up to a dozen first dimension heart-cutting fractions as with the in-line fraction collection device presented in this study. Although, one may also wish to explore other methods for isolating first dimension fractions. Previous studies have demonstrated several configurations that utilize multiloop valve technology to provide 2D functionality to existing HPLC systems by using sample loops within the same valve module, or loops for sample shuttling to multiple second dimension columns [23, 28, 29, 34]. These designs; however, limit the number of first dimension fractions that may be isolated to six or less and are not specifically directed towards quality applications. Overall; however, the best chromatography pairings and fraction collection method will be determined by the product withthis heart-cutting 2D-HPLC method providing a 
valuable tool for monitoring product quality during upstream $\mathrm{mAb}$ production and facilitating realtime adjustments to the cell culture process using QbD and PAT approaches.

\section{Acknowledgements}

This publication reflects the views of the author and should not be construed to represent FDA's views or policies.

\section{Funding Sources}

This project was supported, in part, by an appointment to the Research Participation Program at the Center for Drug Evaluation and Research administered by the Oak Ridge Institute for Science and Education through an interagency agreement between the U.S. Department of Energy and the U.S. Food and Drug Administration. It was also supported by CDER Critical Path project 15-01. 


\section{References}

[1] A.S. Rathore, Roadmap for implementation of quality by design (QbD) for biotechnology products, Trends Biotechnol, 27 (2009) 546-553.

[2] Pharmaceutical cGMPs for the 21st Century: A Risk-Based Approach, DOI (2004).

[3] ICH Harmonised Tripartite Guideline: Development and Manufacture of Drug Substances Q11, The International Conference of Harmonisation of Technical Requirements for Registration of Pharmaceuticals for Human Use, DOI.

[4] ICH Harmonised Tripartite Guideline: Quality Risk Management Q9, The International Conference of Harmonisation of Technical Requirements for Registration of Pharmaceuticals for Human Use, DOI (2005).

[5] ICH Harmonised Tripartite Guideline: Pharmaceutical Quality System Q10, The International Conference of Harmonisation of Technical Requirements for Registration of Pharmaceuticals for Human Use, DOI (2008).

[6] ICH Harmonised Tripartitee Guideline: Pharmaceutical DEvelopment Q8 (R2), The International Conference of Harmonisation of Technical Requirements for Registration of Pharmaceuticals for Human Use, DOI (2009).

[7] E.K. Read, J.T. Park, R.B. Shah, B.S. Riley, K.A. Brorson, A.S. Rathore, Process analytical technology (PAT) for biopharmaceutical products: Part I. concepts and applications, Biotechnol Bioeng, 105 (2010) 276-284.

[8] E.K. Read, R.B. Shah, B.S. Riley, J.T. Park, K.A. Brorson, A.S. Rathore, Process analytical technology (PAT) for biopharmaceutical products: Part II. Concepts and applications, Biotechnol Bioeng, 105 (2010) 285-295.

[9] PAT-A Framework for Innovative Pharamceutical Development, Manufacturing, and Quality Assurance, U.S. Food and Drug Adminitration, DOI (2004).

[10] F. Li, N. Vijayasankaran, A.Y. Shen, R. Kiss, A. Amanullah, Cell culture processes for monoclonal antibody production, MAbs, 2 (2010) 466-479.

[11] H. Nagashima, A. Watari, Y. Shinoda, H. Okamoto, S. Takuma, Application of a quality by design approach to the cell culture process of monoclonal antibody production, resulting in the establishment of a design space, J Pharm Sci, 102 (2013) 4274-4283.

[12] D.A. Pais, M.J. Carrondo, P.M. Alves, A.P. Teixeira, Towards real-time monitoring of therapeutic protein quality in mammalian cell processes, Curr Opin Biotechnol, 30 (2014) 161-167.

[13] N. Gomez, J. Subramanian, J. Ouyang, M.D. Nguyen, M. Hutchinson, V.K. Sharma, A.A. Lin, I.H. Yuk, Culture temperature modulates aggregation of recombinant antibody in cho cells, Biotechnol Bioeng, 109 (2012) 125136.

[14] Y. Jing, M. Borys, S. Nayak, S. Egan, Y.M. Qian, S.H. Pan, Z.J. Li, Identification of cell culture conditions to control protein aggregation of IgG fusion proteins expressed in Chinese hamster ovary cells, Process Biochem, 47 (2012) 69-75.

[15] M. Vazquez-Rey, D.A. Lang, Aggregates in monoclonal antibody manufacturing processes, Biotechnol Bioeng, 108 (2011) 1494-1508.

[16] A.S. Rosenberg, Effects of protein aggregates: an immunologic perspective, AAPS J, 8 (2006) E501-507.

[17] S.A. Berkowitz, J.R. Engen, J.R. Mazzeo, G.B. Jones, Analytical tools for characterizing biopharmaceuticals and the implications for biosimilars, Nat Rev Drug Discov, 11 (2012) 527-540.

[18] P. Hong, S. Koza, E.S. Bouvier, Size-Exclusion Chromatography for the Analysis of Protein Biotherapeutics and their Aggregates, J Liq Chromatogr Relat Technol, 35 (2012) 2923-2950.

[19] S. Fekete, A. Beck, J.L. Veuthey, D. Guillarme, Theory and practice of size exclusion chromatography for the analysis of protein aggregates, J Pharm Biomed Anal, 101 (2014) 161-173.

[20] X. Gjoka, M. Schofield, A. Cvetkovic, R. Gantier, Combined Protein A and size exclusion high performance liquid chromatography for the single-step measurement of mAb, aggregates and host cell proteins, J Chromatogr B Analyt Technol Biomed Life Sci, 972 (2014) 48-52.

[21] J. Horak, A. Ronacher, W. Lindner, Quantification of immunoglobulin G and characterization of process related impurities using coupled protein $A$ and size exclusion high performance liquid chromatography, J Chromatogr A, 1217 (2010) 5092-5102.

[22] M. Lemmerer, A.S. London, A. Panicucci, C. Gutierrez-Vargas, M. Lihon, P. Dreier, Coupled affinity and sizing chromatography: a novel in-process analytical tool to measure titer and trend Fc-protein aggregation, J Immunol Methods, 393 (2013) 81-85. 
[23] H. Han, Y. Miyoshi, K. Ueno, C. Okamura, Y. Tojo, M. Mita, W. Lindner, K. Zaitsu, K. Hamase, Simultaneous determination of $\mathrm{D}$-aspartic acid and $\mathrm{D}$-glutamic acid in rat tissues and physiological fluids using a multi-loop two-dimensional HPLC procedure, J Chromatogr B Analyt Technol Biomed Life Sci, 879 (2011) 3196-3202.

[24] M. Pursch, S. Buckenmaier, Loop-based multiple heart-cutting two-dimensional liquid chromatography for target analysis in complex matrices, Anal Chem, 87 (2015) 5310-5317.

[25] Development of At-Line Assay to Monitor Charge Variants of Mabs During Production, DOI.

[26] M.M. St Amand, B.A. Ogunnaike, A.S. Robinson, Development of at-line assay to monitor charge variants of MAbs during production, Biotechnol Prog, 30 (2014) 249-255.

[27] M.T. Mazur, R.S. Seipert, D. Mahon, Q. Zhou, T. Liu, A platform for characterizing therapeutic monoclonal antibody breakdown products by 2D chromatography and top-down mass spectrometry, AAPS J, 14 (2012) 530541.

[28] D.R. Stoll, D.C. Harmes, J. Danforth, E. Wagner, D. Guillarme, S. Fekete, A. Beck, Direct identification of rituximab main isoforms and subunit analysis by online selective comprehensive two-dimensional liquid chromatography-mass spectrometry, Anal Chem, 87 (2015) 8307-8315.

[29] M. Alvarez, G. Tremintin, J. Wang, M. Eng, Y.H. Kao, J. Jeong, V.T. Ling, O.V. Borisov, On-line characterization of monoclonal antibody variants by liquid chromatography-mass spectrometry operating in a two-dimensional format, Anal Biochem, 419 (2011) 17-25.

[30] C.E. Doneanu, M. Anderson, B.J. Williams, M.A. Lauber, A. Chakraborty, W. Chen, Enhanced Detection of Low-Abundance Host Cell Protein Impurities in High-Purity Monoclonal Antibodies Down to 1 ppm Using lon Mobility Mass Spectrometry Coupled with Multidimensional Liquid Chromatography, Anal Chem, 87 (2015) 10283-10291.

[31] C.E. Doneanu, A. Xenopoulos, K. Fadgen, J. Murphy, S.J. Skilton, H. Prentice, M. Stapels, W. Chen, Analysis of host-cell proteins in biotherapeutic proteins by comprehensive online two-dimensional liquid chromatography/mass spectrometry, MAbs, 4 (2012) 24-44.

[32] R.E. Birdsall, H. Shion, F.W. Kotch, A. Xu, T.J. Porter, W. Chen, A rapid on-line method for mass spectrometric confirmation of a cysteine-conjugated antibody-drug-conjugate structure using multidimensional chromatography, MAbs, 7 (2015) 1036-1044.

[33] M. Sorensen, D.C. Harmes, D.R. Stoll, G.O. Staples, S. Fekete, D. Guillarme, A. Beck, Comparison of originator and biosimilar therapeutic monoclonal antibodies using comprehensive two-dimensional liquid chromatography coupled with time-of-flight mass spectrometry, MAbs, 8 (2016) 1224-1234.

[34] G. Vanhoenacker, I. Vandenheede, F. David, P. Sandra, K. Sandra, Comprehensive two-dimensional liquid chromatography of therapeutic monoclonal antibody digests, Anal Bioanal Chem, 407 (2015) 355-366. 
Table 1. Components of Agilent 1200 Series HPLC system and in-line fraction collection device.

\begin{tabular}{ll}
\hline Name & Part No. \\
\hline 1260 Autosampler & G1329B \\
1260 Degasser $(x$ 2) & G1322A \\
1290 DAD (D2) & G4212A \\
1290 Thermostat & G1330B \\
12/13 SelValve & G1160A \\
DAD (D1) & G1315D \\
Quaternary Pump (x 2) & G1311A \\
Temperature-controlled column compartment & G1316A \\
\hline
\end{tabular}


Table 2. Elution volumes of Blue Dextran 2000 and SEC standard proteins. The elution volume of the first Blue Dextran peak is equivalent to the column void volume $\left(V_{o}\right)$. At least three independent experiments were conducted for all conditions. Values provided in terms or mean \pm SEM (standard estimate of mean).

\begin{tabular}{|c|c|c|c|c|c|}
\hline \multirow{2}{*}{$\begin{array}{l}\text { Sample } \\
\text { Loop \# }\end{array}$} & \multirow{2}{*}{ Analyte } & \multicolumn{2}{|c|}{ Elution Volume $\left(V_{e}\right)$} & \multicolumn{2}{|c|}{ Partition Coefficient $\left(K_{a v}\right)$} \\
\hline & & Loading at $0 \mathrm{~min}$ & $\begin{array}{l}\text { Loading at } 10 \text { or } 20 \mathrm{~min} \\
\text { (Normalized to } 0 \mathrm{~min} \text { ) }\end{array}$ & $\begin{array}{l}\text { Loading at } 10 \text { or } 20 \mathrm{~min} \\
\text { (Normalized to } 0 \mathrm{~min} \text { ) }\end{array}$ & $\begin{array}{c}\text { \% Difference, } \\
\text { Compared to Loop \#1 }\end{array}$ \\
\hline \multirow{5}{*}{1} & Blue Dextran 2000 & $0.821 \pm 0.002$ & $0.819 \pm 0.011$ & -- & -- \\
\hline & a. Thyroglobulin $669 \mathrm{kDa}$ & & $0.928 \pm 0.002$ & $0.065 \pm 0.001$ & -- \\
\hline & b. Aldolase 158 kDa & & $1.251 \pm 0.001$ & $0.258 \pm 0.001$ & -- \\
\hline & c. Ovalbumin 44 kDa & & $1.408 \pm 0.001$ & $0.352 \pm 0.001$ & -- \\
\hline & d. Ribonuclease A $13.7 \mathrm{kDa}$ & & $1.653 \pm 0.001$ & $0.499 \pm 0.001$ & -- \\
\hline \multirow{5}{*}{2} & Blue Dextran 2000 & $0.816 \pm 0.002$ & $0.816 \pm 0.004$ & -- & \\
\hline & a. Thyroglobulin 669 kDa & & $0.925 \pm 0.001$ & $0.065 \pm 0.0003$ & 0.133 \\
\hline & b. Aldolase 158 kDa & & $1.249 \pm 0.001$ & $0.258 \pm 0.0003$ & 0.189 \\
\hline & c. Ovalbumin $44 \mathrm{kDa}$ & & $1.406 \pm 0.001$ & $0.352 \pm 0.001$ & 0.086 \\
\hline & d. Ribonuclease A $13.7 \mathrm{kDa}$ & & $1.651 \pm 0.001$ & $0.498 \pm 0.0004$ & 0.413 \\
\hline
\end{tabular}


Table 3. Standard heart-cutting 2D HPLC Method: Timing of automated switching of the valves of the in-line fraction collection device for fractionation and subsequent loading of column 2.

\begin{tabular}{ccc}
\hline $\begin{array}{c}\text { HPLC Valve } \\
\text { Position }\end{array}$ & \multicolumn{2}{c}{$\begin{array}{c}\text { In-line Fraction Collector } \\
\text { Valve Switching }\end{array}$} \\
\cline { 2 - 3 } & Time & Open Valve/Sample Loop \# \\
\hline \multirow{2}{*}{$1 \rightarrow 10$} & $0 \mathrm{~min}$ & 1 \\
& $5.51 \mathrm{~min}$ & 2 \\
& $6.01 \mathrm{~min}$ & 3 \\
$1 \rightarrow 2$ & $10 \mathrm{~min}$ & 1 \\
& $20 \mathrm{~min}$ & 2 \\
\hline
\end{tabular}


Table 4. $K_{a v}$ values for peaks resolved by SEC from each of the sample loops following standard heart-cutting.

\begin{tabular}{ccc}
\hline Loop\# & Peak \# & $\boldsymbol{K}_{\boldsymbol{a} \boldsymbol{v}}$ \\
\hline \multirow{3}{*}{$\mathbf{1}$} & 1 & 0.18 \\
& 2 & 0.35 \\
& 3 & 0.58 \\
& 4 & 1.50 \\
\multirow{2}{*}{$\mathbf{2}$} & 1 & 0.23 \\
& 2 & 0.59 \\
& 3 & 1.52 \\
\hline
\end{tabular}


Table 5. Sequential heart-cutting 2D-HPLC Method: Timing of automated switching of the valves of the in-line fraction collection device for sample collection and subsequent loading of column 2 .

\begin{tabular}{|c|c|c|}
\hline \multirow{2}{*}{$\begin{array}{l}\text { HPLC Valve } \\
\text { Position }\end{array}$} & \multicolumn{2}{|c|}{$\begin{array}{c}\text { In-Line Fraction Collector } \\
\text { Valve Switching }\end{array}$} \\
\hline & Time, min & Open Valve/Sample Loop \# \\
\hline \multirow{11}{*}{$1 \rightarrow 10$} & 0 & 1 \\
\hline & 4.51 & 2 \\
\hline & 4.71 & 3 \\
\hline & 4.91 & 4 \\
\hline & 5.21 & 5 \\
\hline & 5.41 & 6 \\
\hline & 5.61 & 7 \\
\hline & 5.81 & 8 \\
\hline & 6.01 & 9 \\
\hline & 6.21 & 10 \\
\hline & 6.41 & 11 \\
\hline \multirow{10}{*}{$1 \rightarrow 2$} & 10 & 1 \\
\hline & 20 & 2 \\
\hline & 30 & 3 \\
\hline & 40 & 4 \\
\hline & 50 & 5 \\
\hline & 60 & 6 \\
\hline & 70 & 7 \\
\hline & 80 & 8 \\
\hline & 90 & 9 \\
\hline & 100 & 10 \\
\hline
\end{tabular}


Table 6. $K_{a v}$ values for peaks resolved from each of the ten sample loops following sequential heart-cutting.

\begin{tabular}{ccc}
\hline Loop\# & Peak \# & $\boldsymbol{K}_{\boldsymbol{a v}}$ \\
\hline $\mathbf{1}$ & 1 & 0.42 \\
$\mathbf{2}$ & 1 & 0.60 \\
$\mathbf{3}$ & 1 & 0.41 \\
$\mathbf{4}$ & 1 & 0.31 \\
& 2 & 0.37 \\
$\mathbf{5}$ & 1 & 0.28 \\
$\mathbf{6}$ & 1 & 0.28 \\
$\mathbf{7}$ & 2 & 0.57 \\
$\mathbf{8}$ & 1 & 0.22 \\
$\mathbf{9}$ & 1 & 0.20 \\
$\mathbf{1 0}$ & 1 & 0.26 \\
& 1 & 0.33 \\
& 2 & 0.62 \\
\hline
\end{tabular}




\section{Figure Legends}

Figure 1. SEC analysis of model IgG1 protein subjected to $65^{\circ} \mathrm{C}$ insult for 3 days.

Figure 2. In-line fraction collection device. A) Two electronically-controlled Agilent 12/13 SelValve systems with twelve $100 \mu \mathrm{L}$ loops connecting each corresponding valve. B) Schematic representation of rotating valve configuration. Only one valve can be in the open position at any given time. Flow originating from the inlet port (valve 13) of the top valve system can be directed to the open valve (valve 1-12), through the sample loop and the corresponding open valve (valve 1-12) in the bottom valve system, and exits through the outlet port (valve 13) on the bottom valve system. Automated switching of valves allows for isolation and release of fractions from protein peaks of interest.

Figure 3. Valve Configuration for 2D-HPLC system. Pump 1 and 2 are used to control and maintain continuous solvent flow through column 1 (Protein A) and column 2 (SEC), respectively. UV detectors D1 and D2 are A) When the 2D-HPLC system is in the $1 \rightarrow 10$ (or clockwise) direction, purified samples may be collected via the in-line fraction collector. B) After switching the valve to the $1 \rightarrow 2$ (or counter-clockwise) direction, fractions isolated within the sample loops can be sequentially loaded onto column 2. D1, first UV detector; D2, second UV detector.

Figure 4. POROS A20 Protein A standard curve.

Figure 5. An SEC Protein Standard Mix consisting of (a) Thyroglobulin 669 kDa, (b) Aldolase 158 kDa, (c) Ovalbumin 44 $\mathrm{kDa}$, and (d) Ribonuclease A 13.7 kDA,. The SEC standard is loaded onto column two from sample loops one and two of the in-line fraction collection device at $10 \mathrm{~min}$ and $20 \mathrm{~min}$, respectively.

Figure 6. Standard curve for Agilent Advanced Bio SEC $300 \AA ̊$ column.

Figure 7. A) Protein A purification of thermally-aggregated $m A b$ using a linear gradient of $0.1 \mathrm{M}$ acetic acid. Two elution peaks are observed. Fractions from each peak are simultaneously shunted to the in-line fraction collector for isolation, and B) evaluated by SEC after sequential loading onto the second dimension column at 10 and 20 min, respectively. C) Zoomed in view of SEC shows resolution of protein aggregation. Second dimension peaks are labeled based on calculated $K_{a v}$ values.

Figure 8. A) Protein A purification of a thermally-aggregated $m A b$ using a linear gradient of $0.1 \mathrm{M}$ acetic acid. A series of fractions from the aggregate peak and monomer peak are simultaneously collected via the in-line fraction collection device. B) SEC of each of the collected fractions after sequential loading onto the second dimension column every 10 min. Second dimension peaks are labeled based on calculated $K_{a v}$ values. 
Figure 1

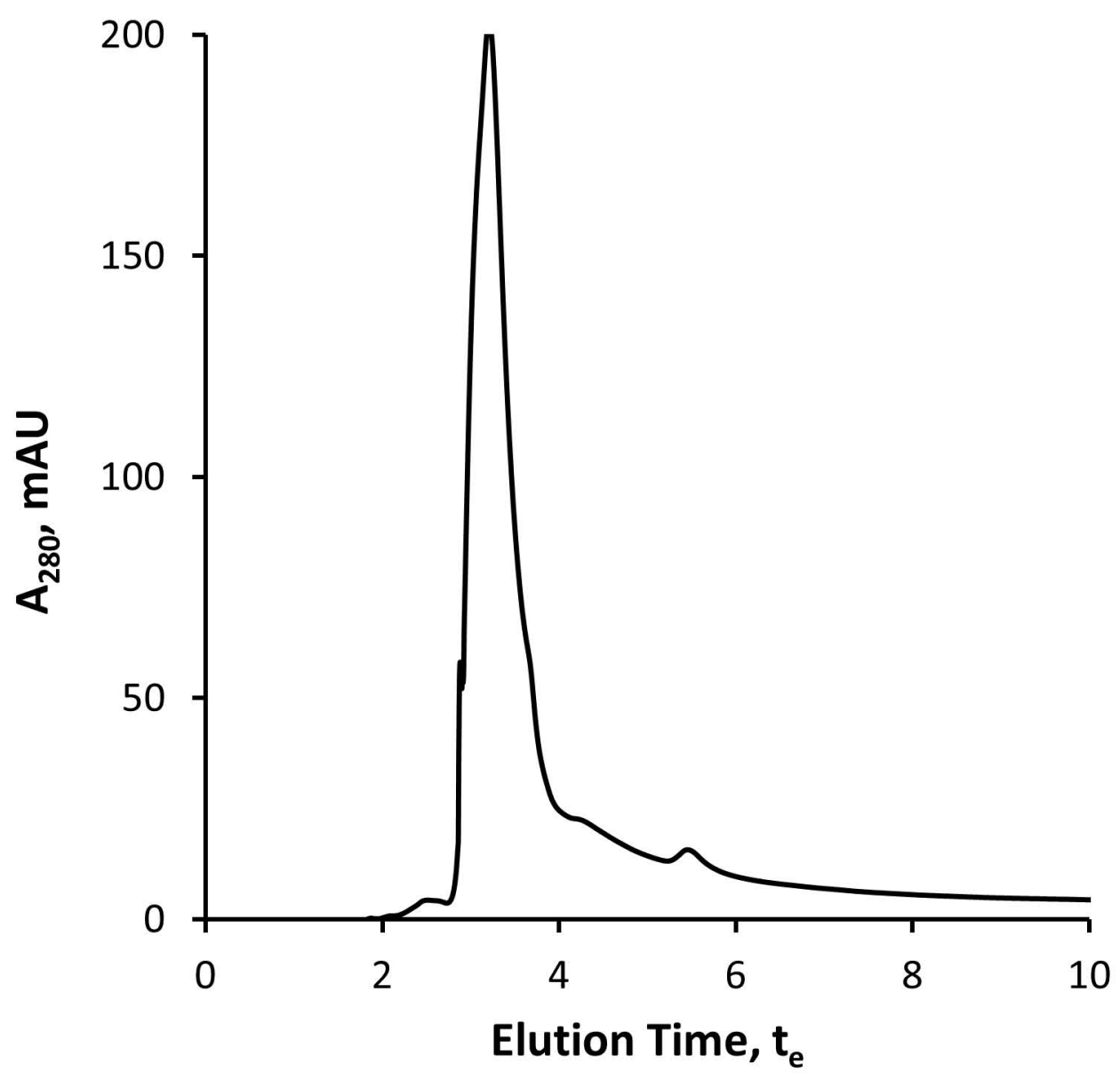


Figure 2
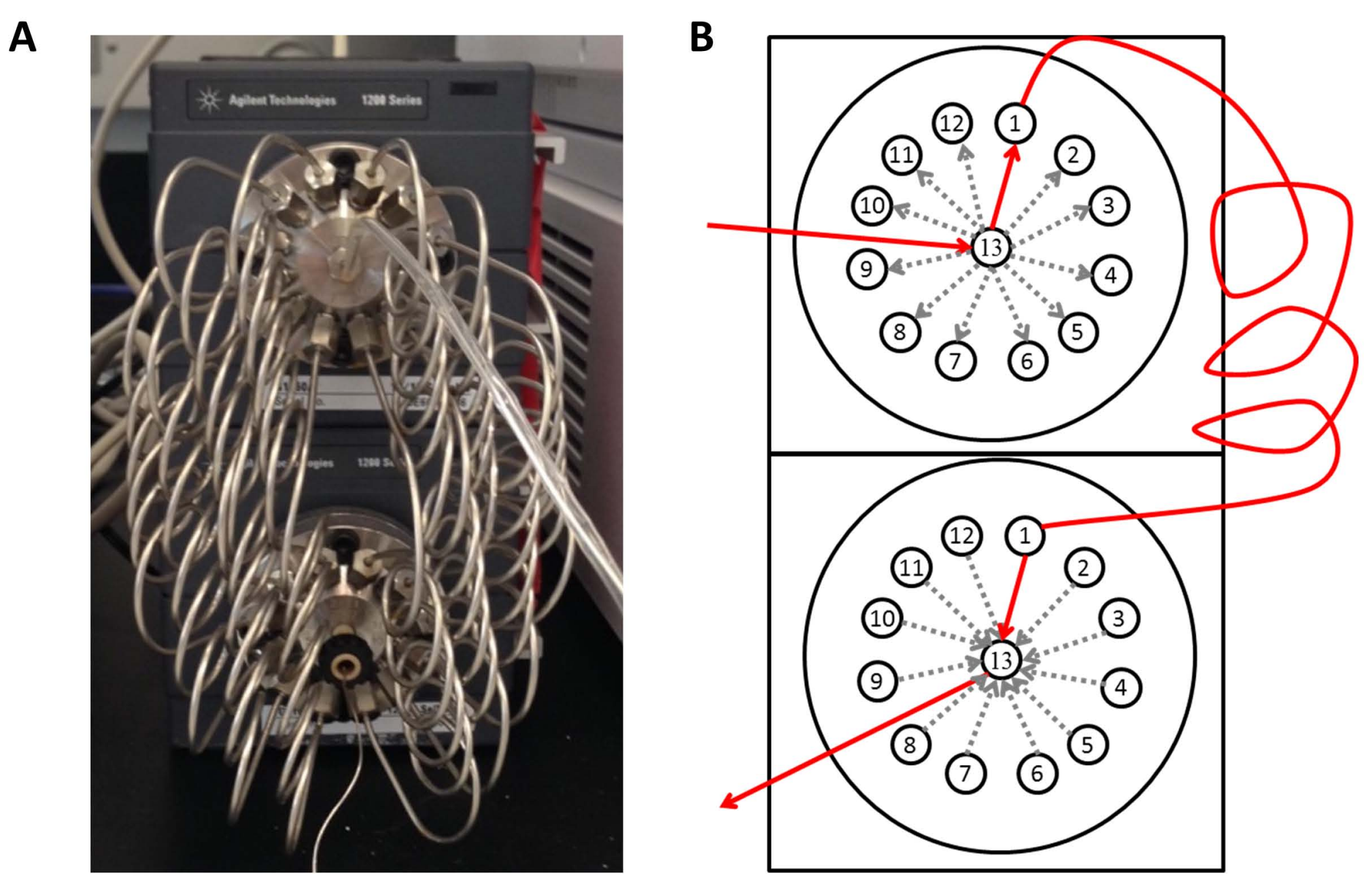
Figure 3

A

Flow from Pump 2

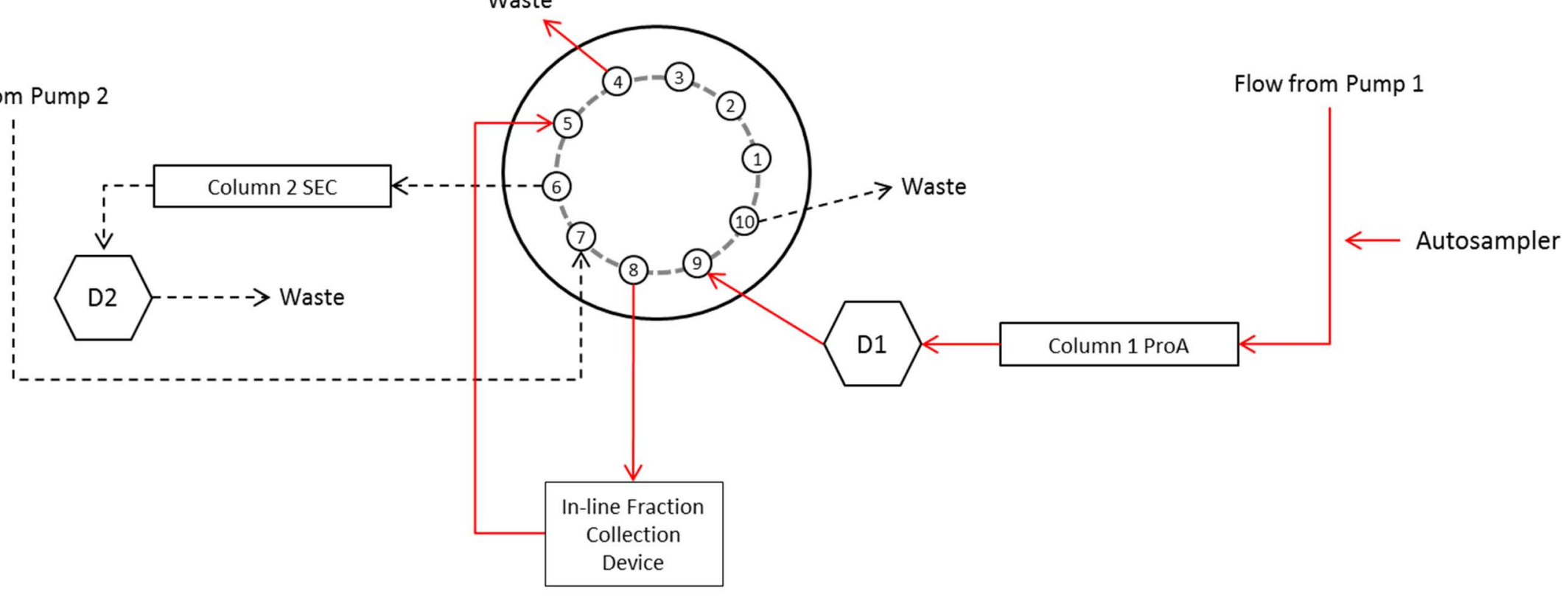

B

T

Flow from Pump 2

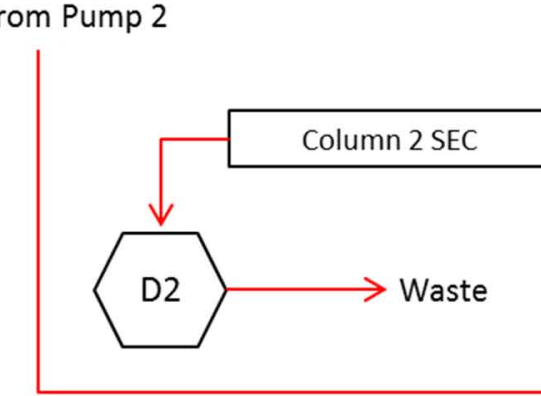

Waste 
Figure 4

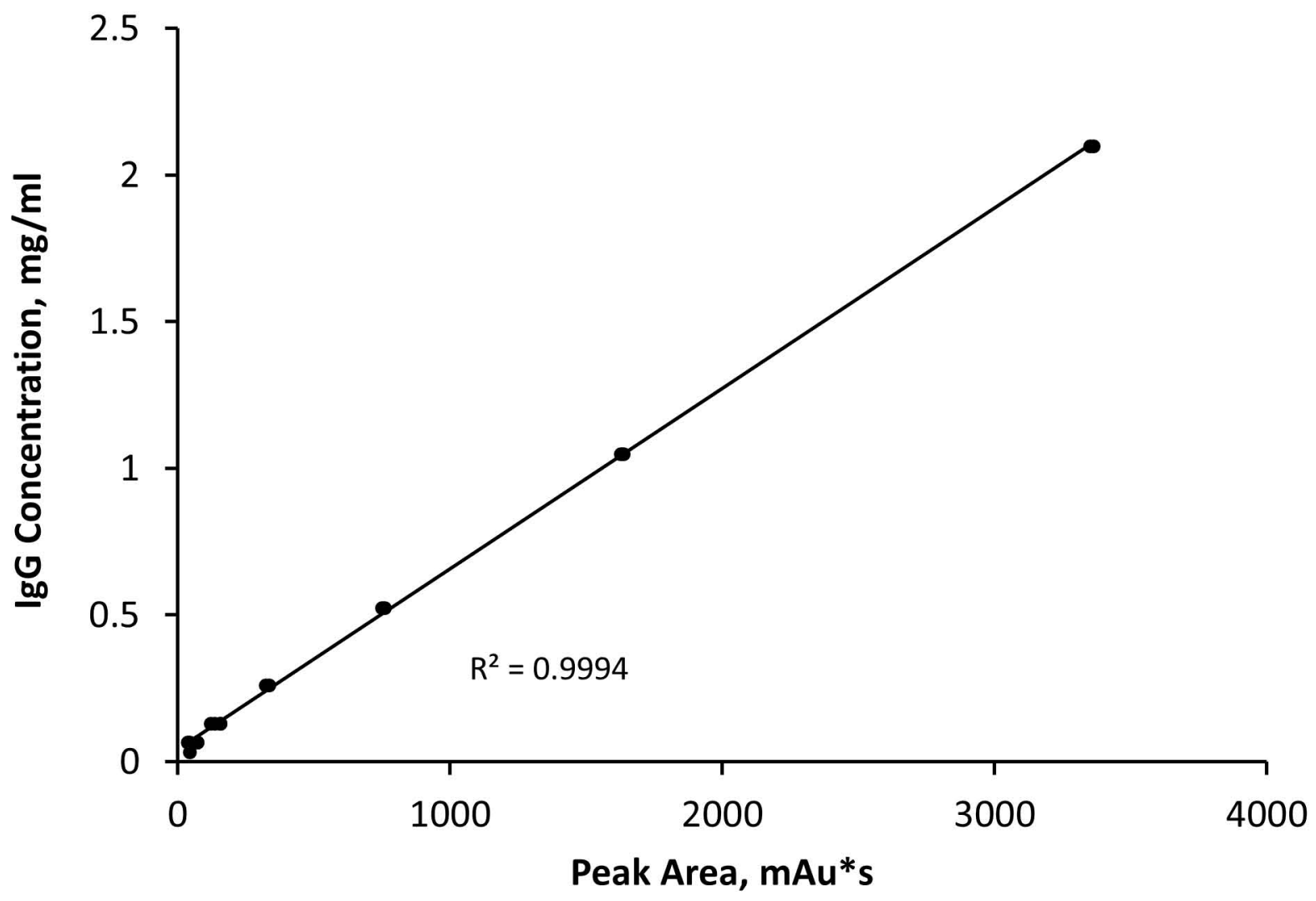


Figure 5

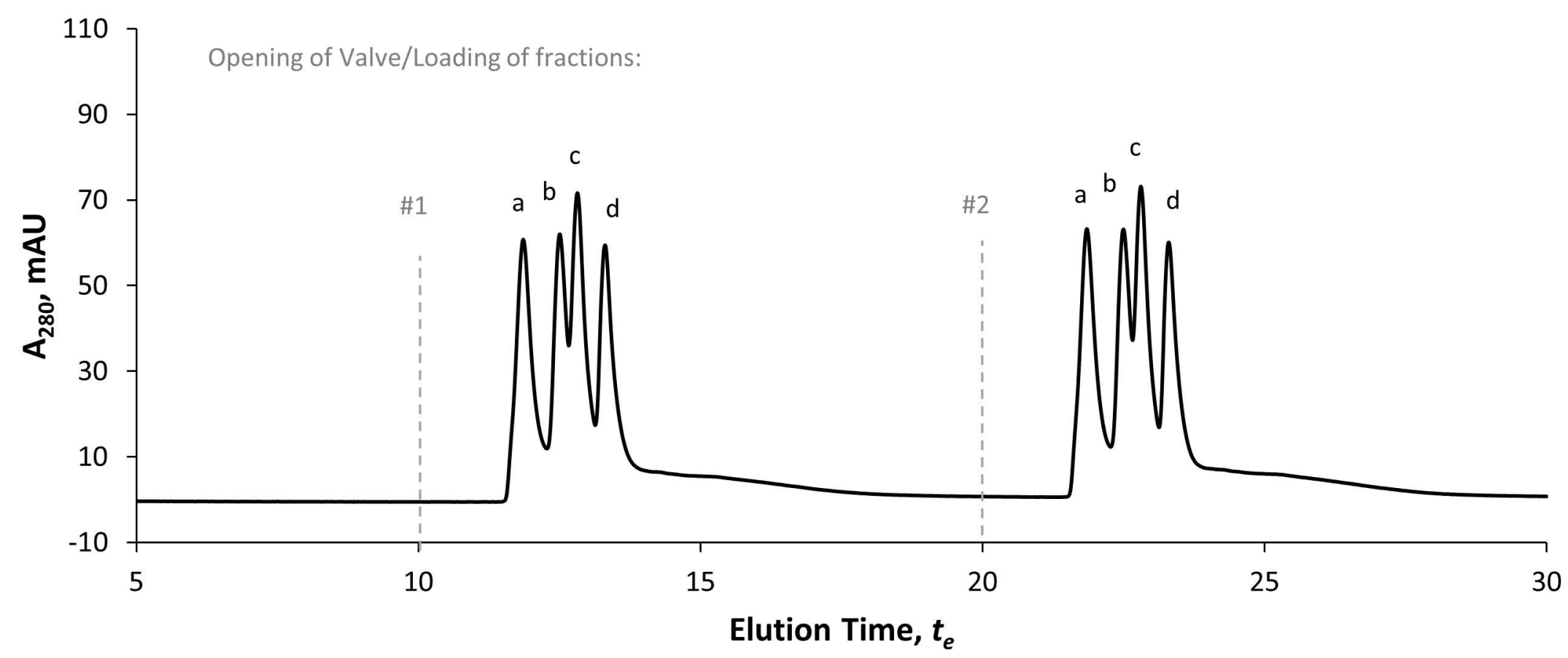


Figure 6

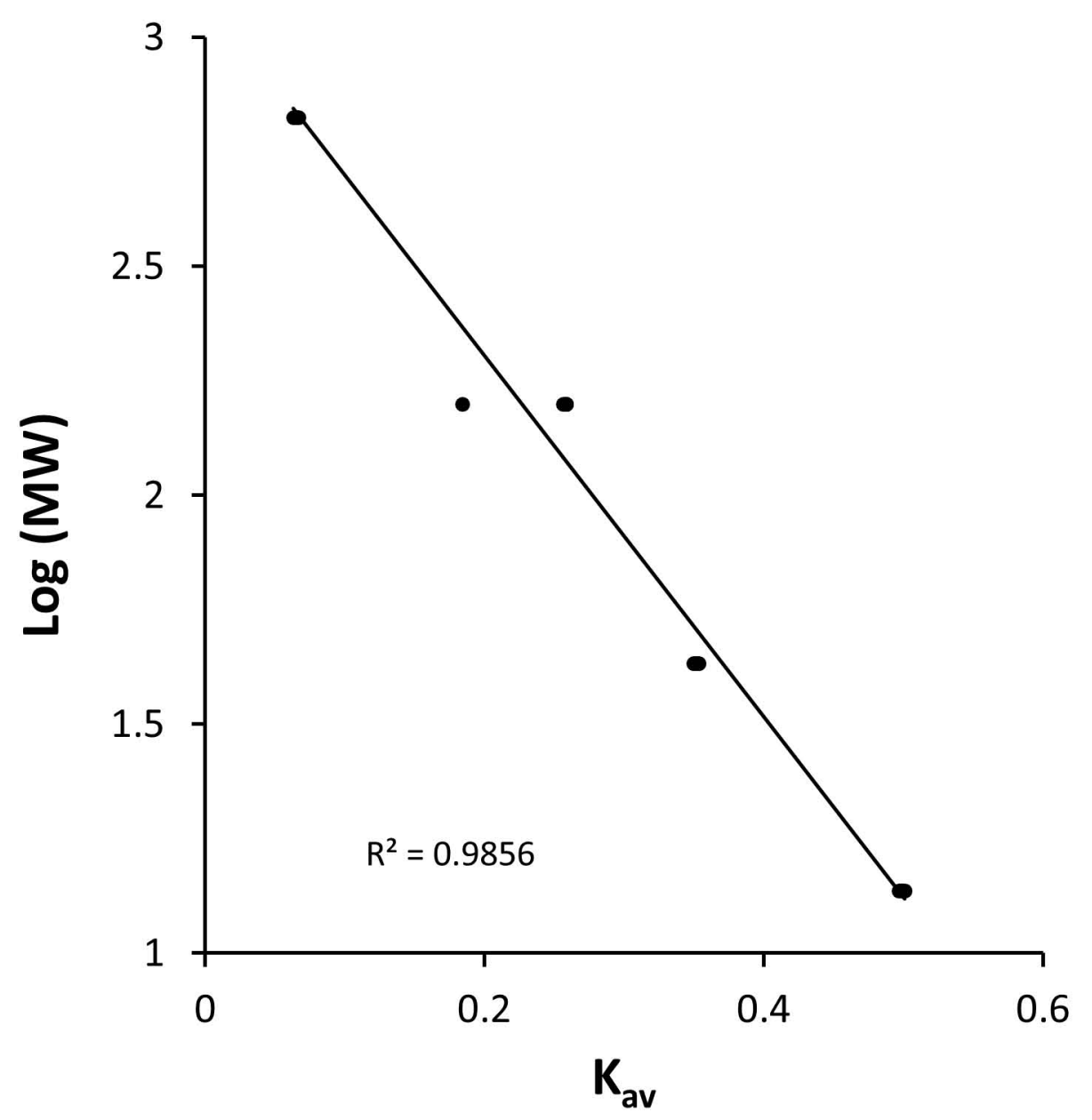


Figure 7A

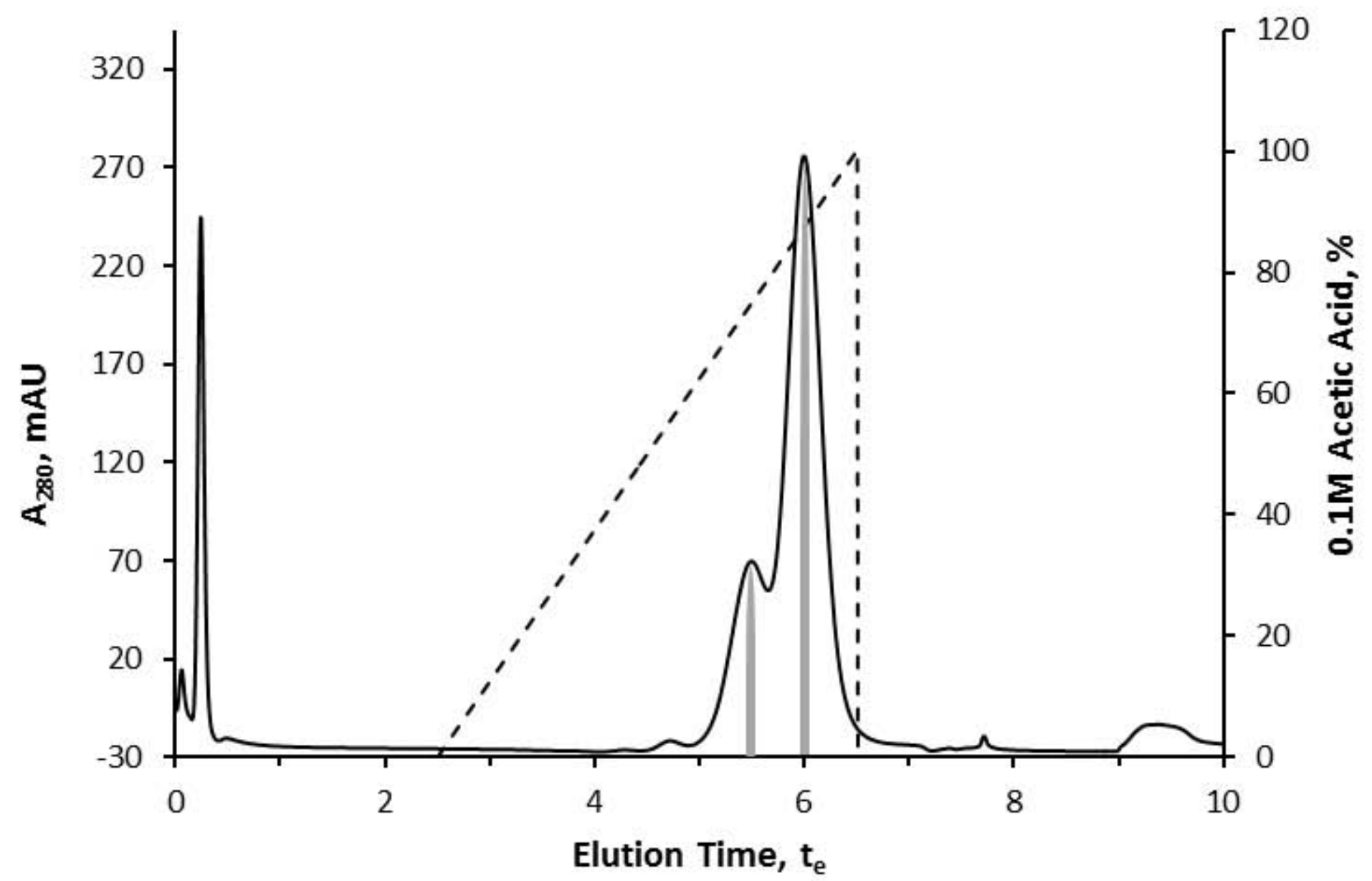


Figure 7A

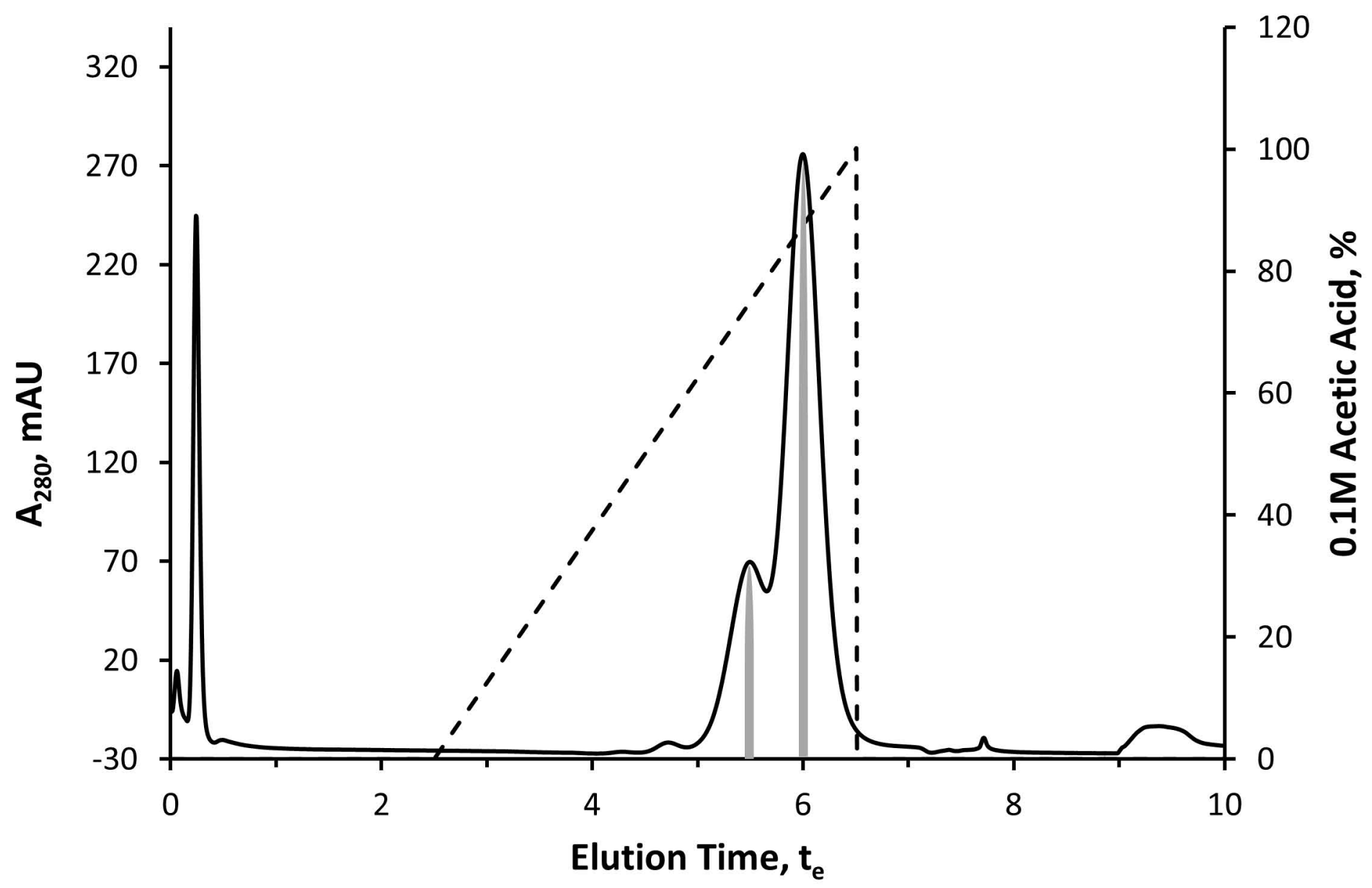


Figure 7B

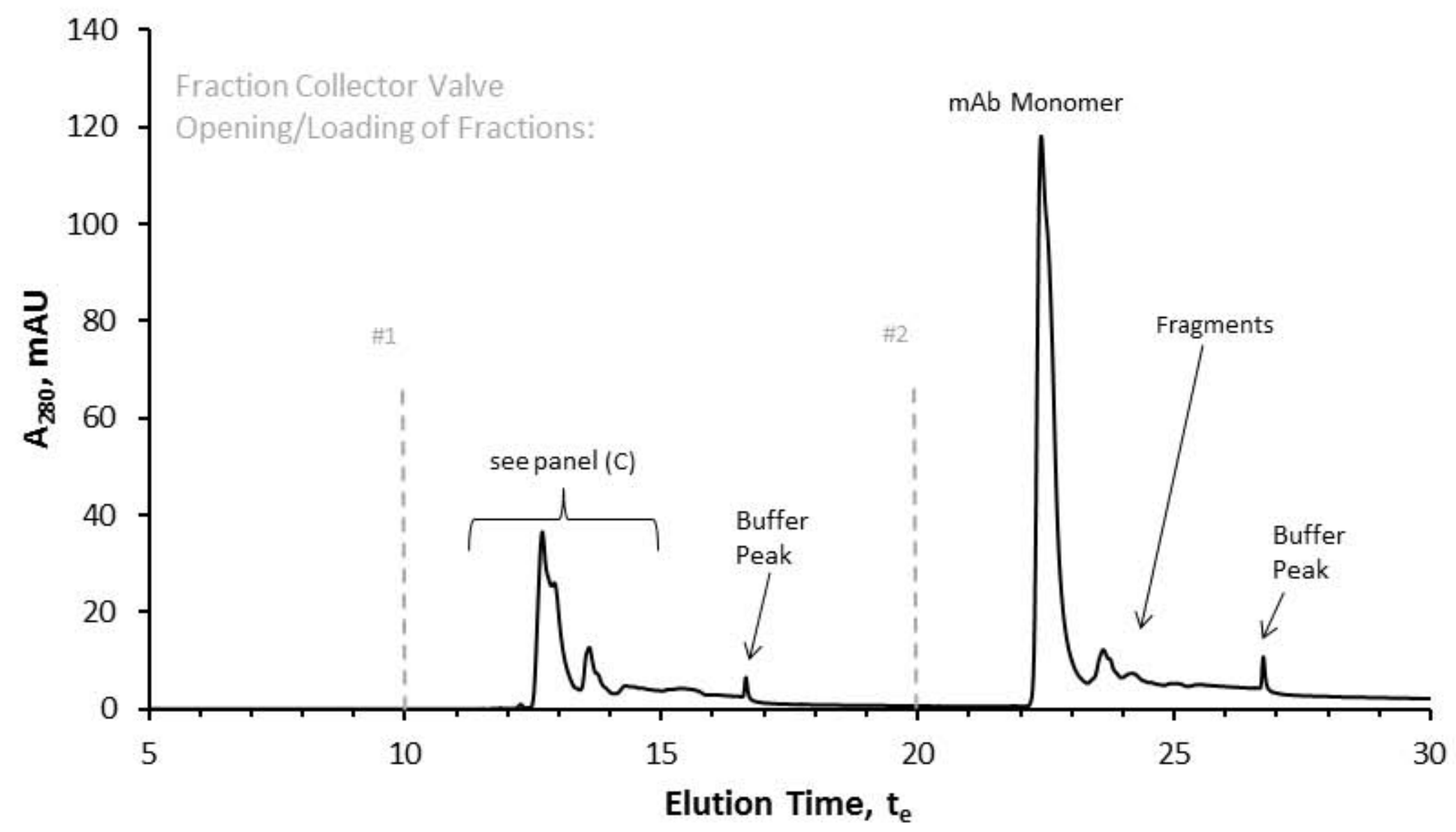


Figure 7B

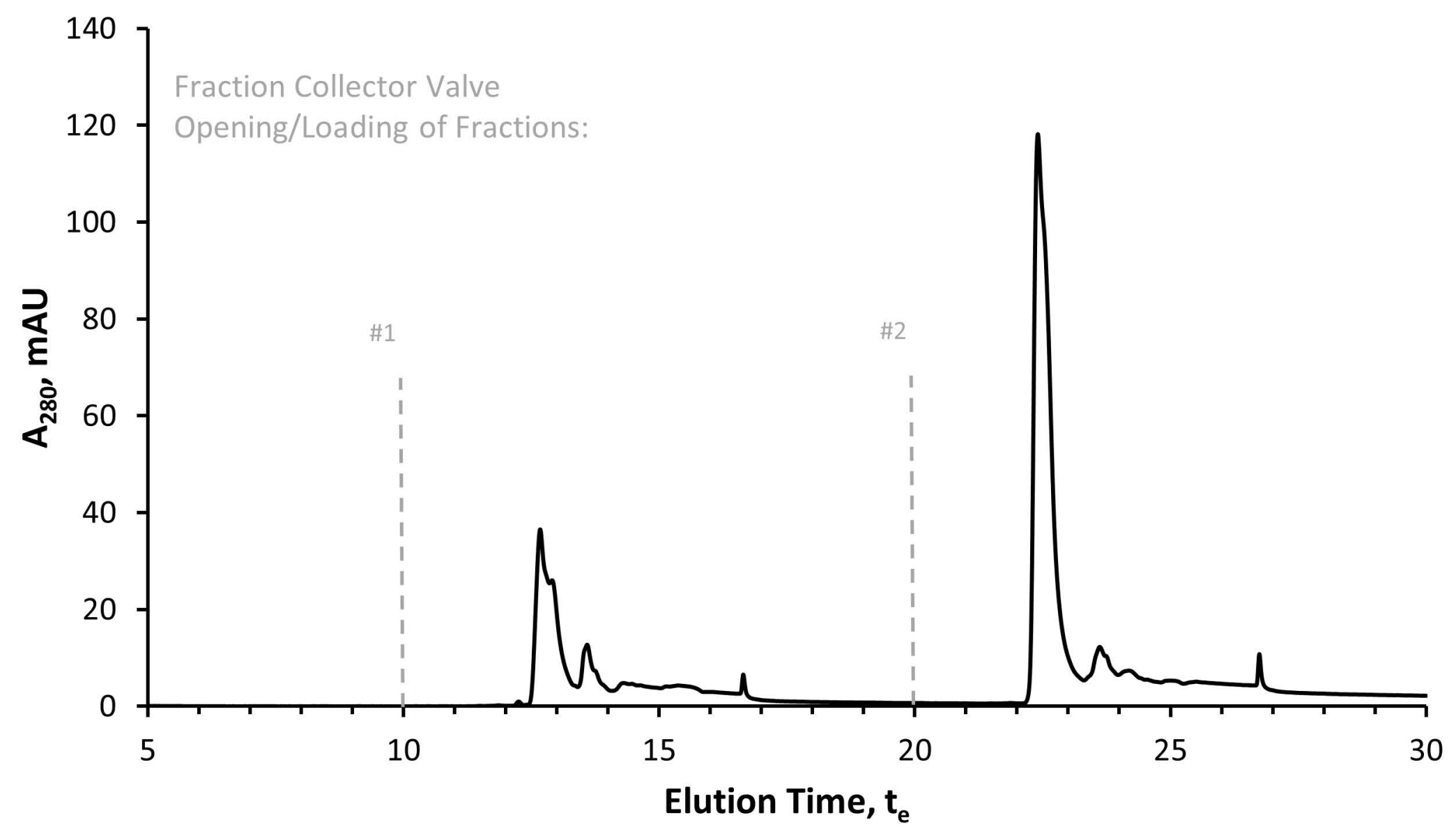


Figure 7C

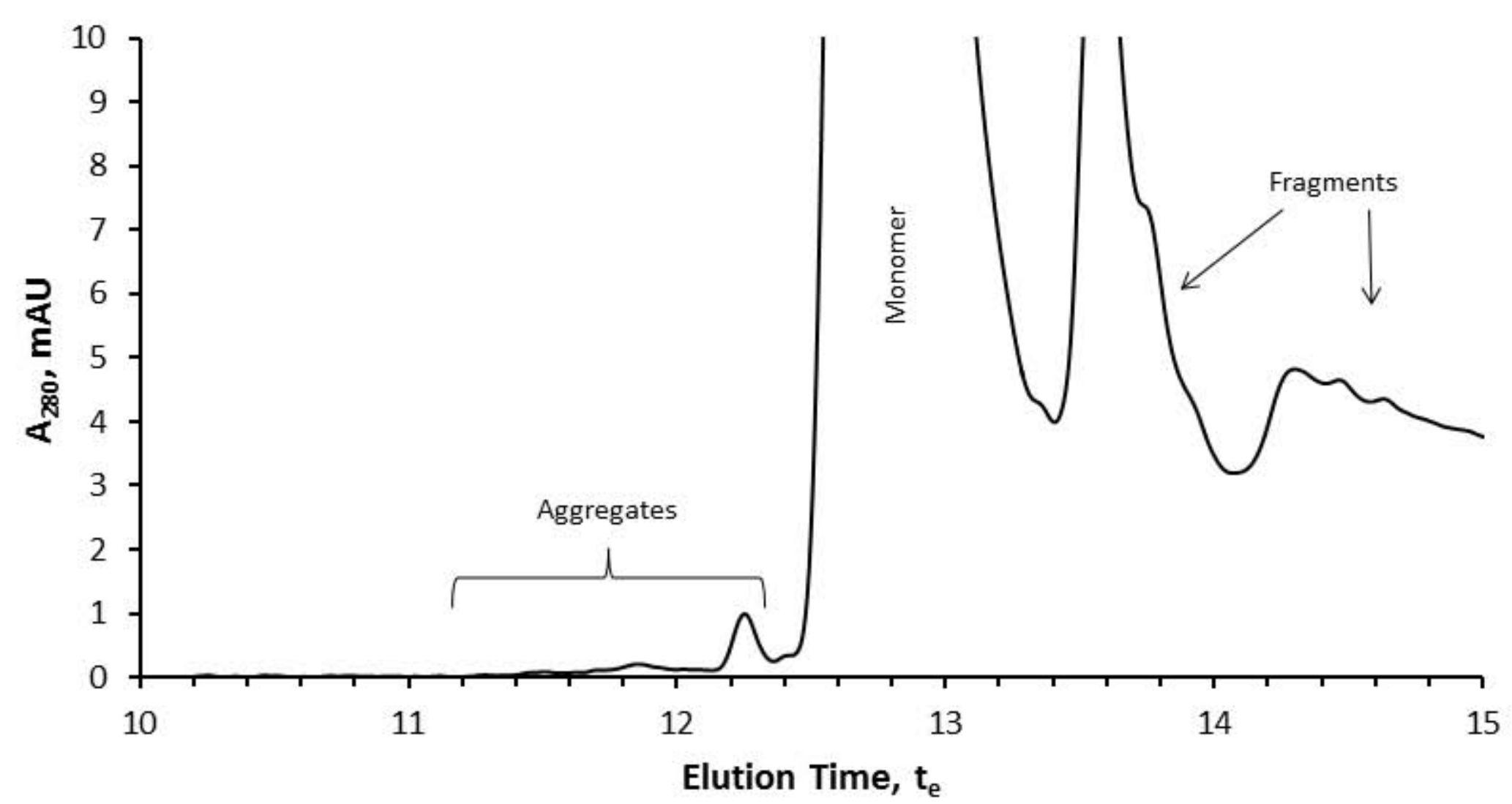


Figure $7 C$

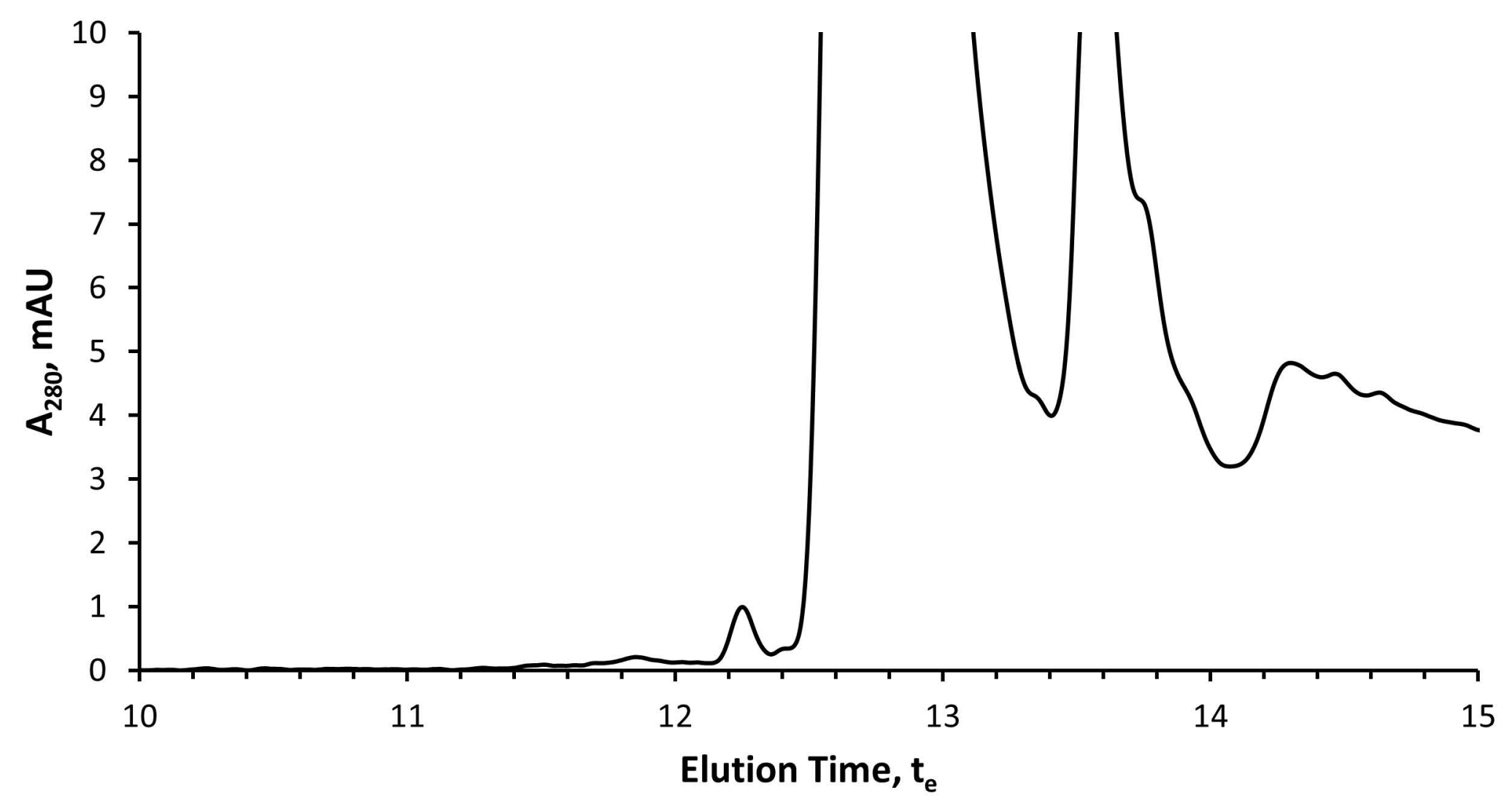


Figure 8A

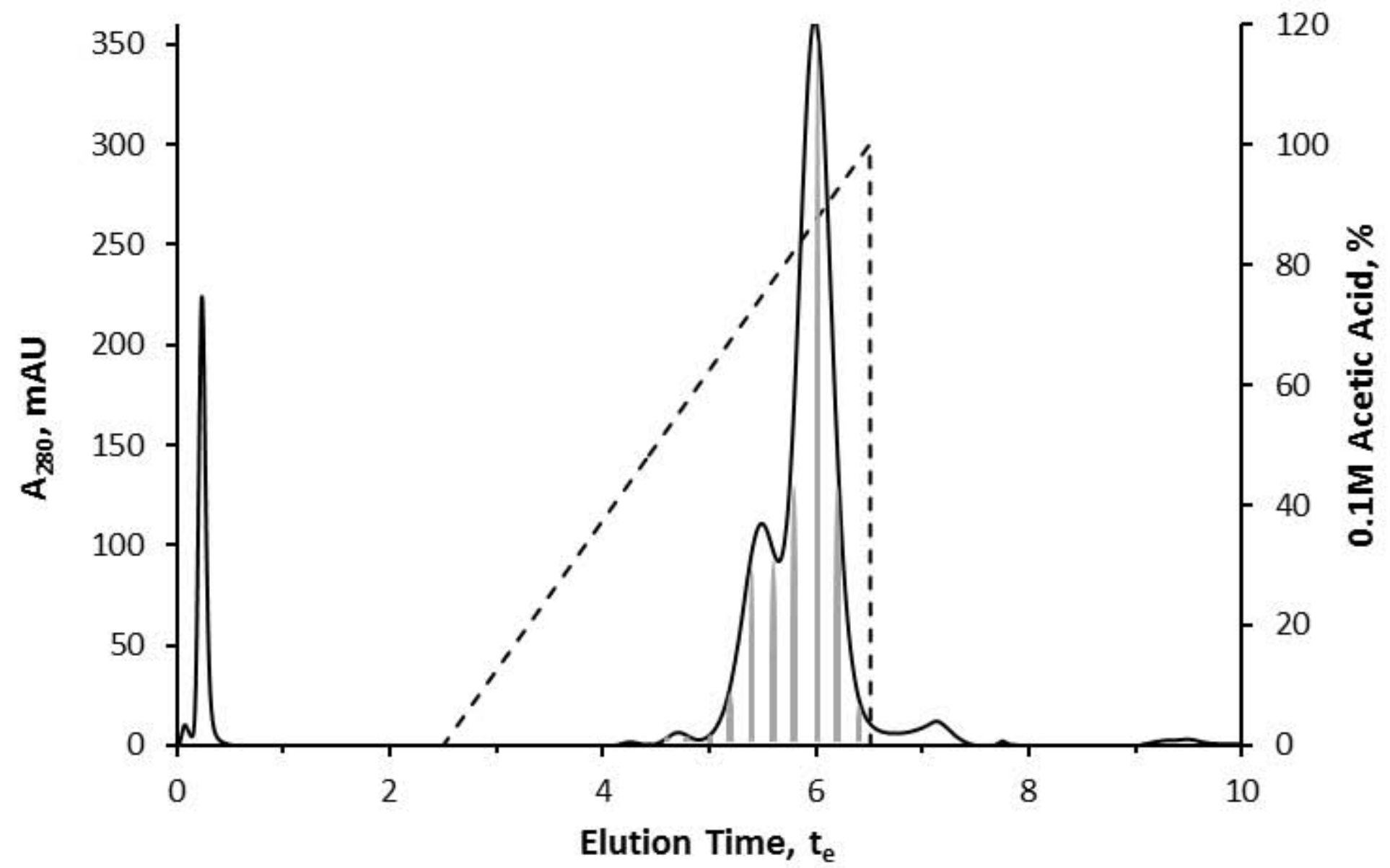


Figure 8A

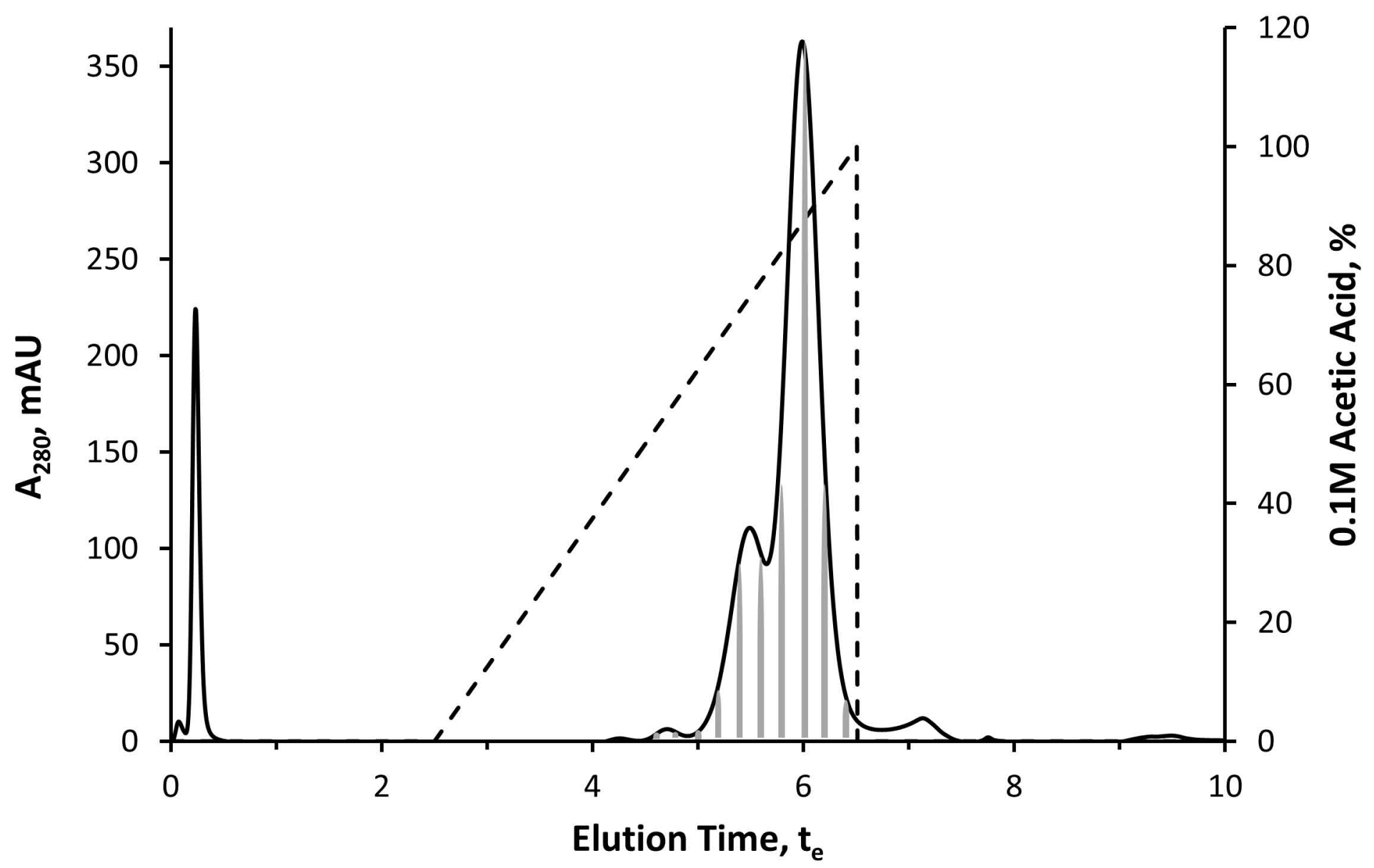




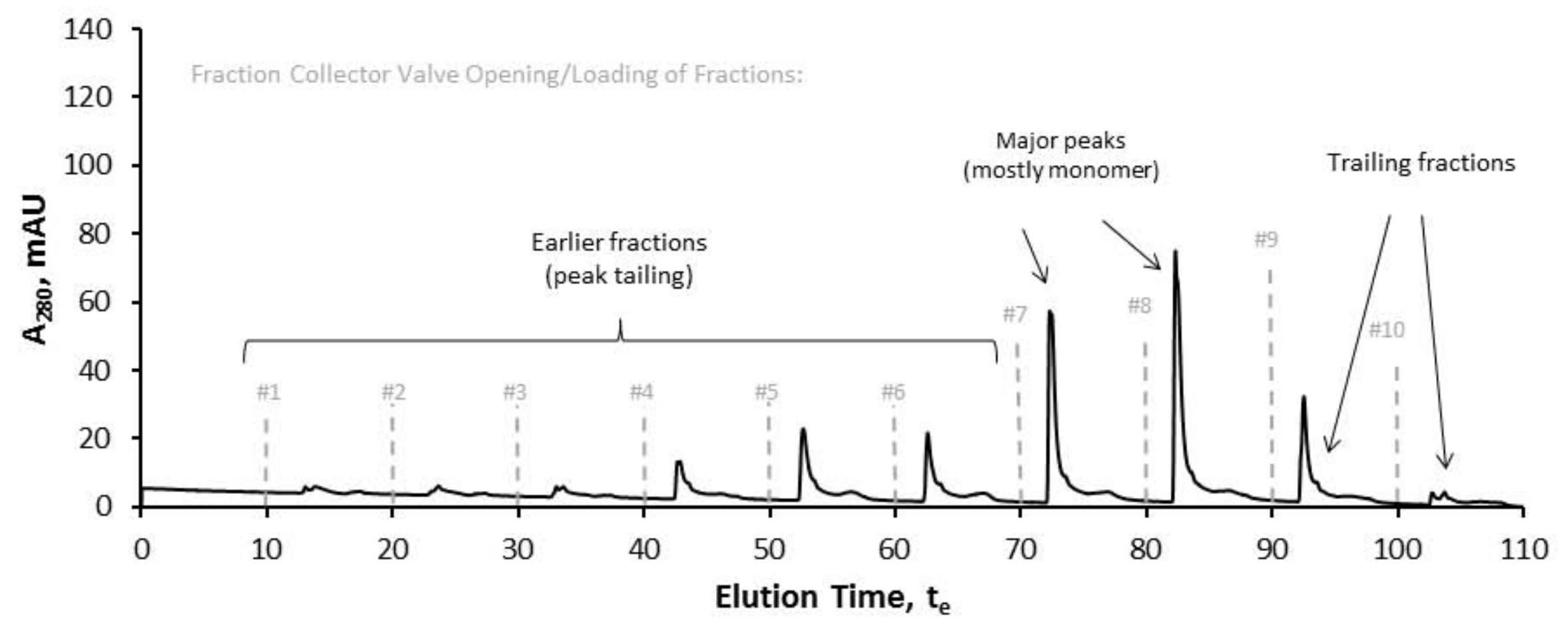


Figure 8B

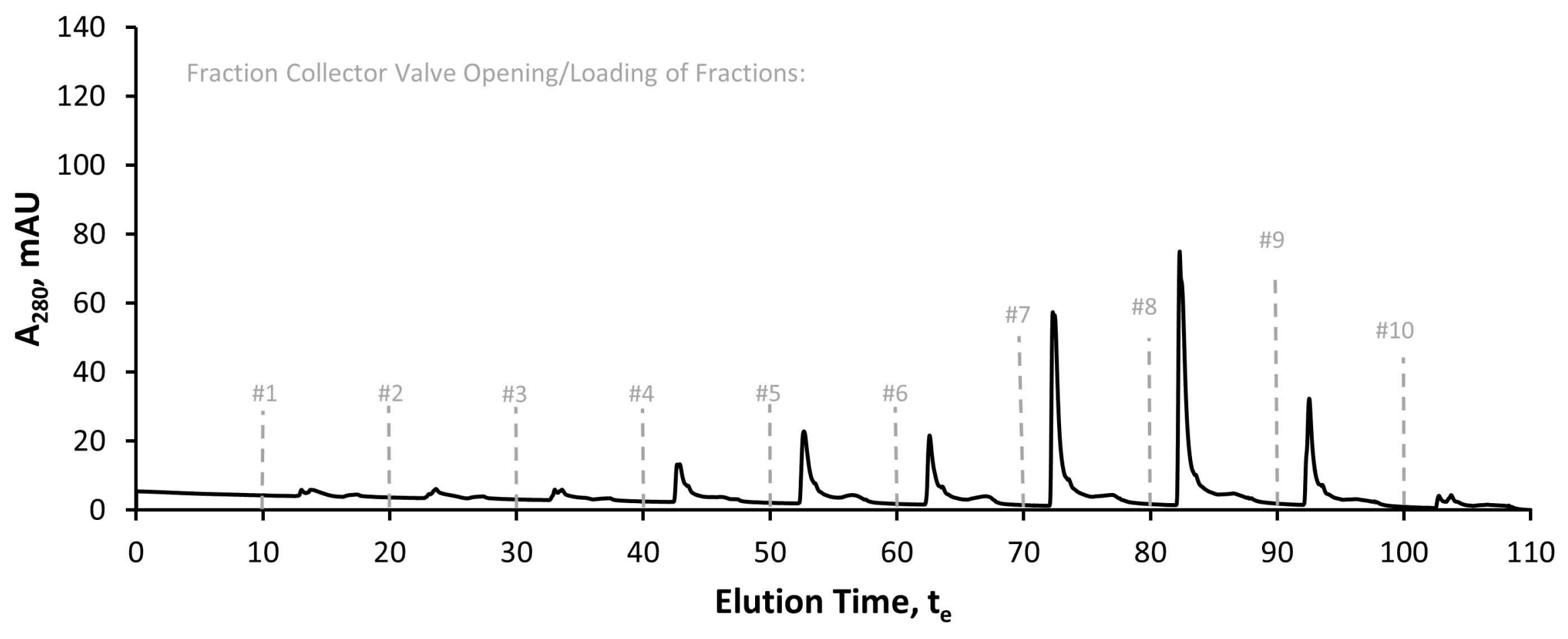

